IZA DP No. 6762

Risk Preferences Are Not Time Preferences:

Comment

Stephen L. Cheung

July 2012 


\title{
Risk Preferences Are Not Time Preferences: Comment
}

\author{
Stephen L. Cheung \\ University of Sydney \\ and IZA
}

\section{Discussion Paper No. 6762 \\ July 2012}

IZA
P.O. Box 7240
53072 Bonn
Germany

Phone: +49-228-3894-0

Fax: +49-228-3894-180

E-mail: iza@iza.org

\begin{abstract}
Any opinions expressed here are those of the author(s) and not those of IZA. Research published in this series may include views on policy, but the institute itself takes no institutional policy positions.

The Institute for the Study of Labor (IZA) in Bonn is a local and virtual international research center and a place of communication between science, politics and business. IZA is an independent nonprofit organization supported by Deutsche Post Foundation. The center is associated with the University of Bonn and offers a stimulating research environment through its international network, workshops and conferences, data service, project support, research visits and doctoral program. IZA engages in (i) original and internationally competitive research in all fields of labor economics, (ii) development of policy concepts, and (iii) dissemination of research results and concepts to the interested public.
\end{abstract}

IZA Discussion Papers often represent preliminary work and are circulated to encourage discussion. Citation of such a paper should account for its provisional character. A revised version may be available directly from the author. 


\section{ABSTRACT}

\section{Risk Preferences Are Not Time Preferences: Comment ${ }^{*}$}

Andreoni and Sprenger (in press) report evidence that distinct utility functions govern choices under certainty and risk. I investigate the robustness of their result to the experimental design. I find that the effect disappears completely when a multiple price list is used instead of a convex time budget design. Also, the effect is reduced by half when sooner and later payment risks are realized using a single lottery instead of two independent lotteries. The result is thus partially driven by intertemporal diversification, suggesting an explanation in terms of concavity of the intertemporal, and not only the atemporal, utility function.

JEL Classification: C91, D03, D81, D90

Keywords: intertemporal choice, risk and certainty, convex time budget, multiple price list

Corresponding author:

Stephen L. Cheung

The University of Sydney

School of Economics

Merewether Building $\mathrm{HO} 4$

Sydney NSW 2006

Australia

E-mail: Stephen.Cheung@sydney.edu.au

\footnotetext{
* I thank Glenn Harrison, Graham Loomes and Robert Slonim, and participants at the Australia and New Zealand Workshop on Experimental Economics at Monash University in August 2011, the AsiaPacific meetings of the Economic Science Association at Xiamen University in December 2011, the Sydney Experimental Brownbag Seminar at the University of New South Wales in May 2012, the International meetings of the Economic Science Association at New York University in June 2012, and the Foundations and Applications of Utility, Risk and Decision Theory conference at Georgia State University in July 2012. This research was funded in part by the Faculty of Arts and Social Sciences at The University of Sydney. Approval to conduct the research was granted by The University of Sydney Human Research Ethics Committee, under protocol number 13914. The author declares that he has no relevant or material financial interests that relate to the research described in this paper.
} 
The past decade has seen rapid advances in the development of both experimental designs and estimation procedures to measure the utility and discount functions that govern individual choices over time. These advances are significant both because many important economic decisions entail consequences at different points in time, and because a substantial earlier literature found wide disparities in estimated discount rates - including many that seem extraordinarily large. ${ }^{1}$ In a recent contribution, Andreoni and Sprenger (2012b, hereinafter A\&S) report evidence of a "disproportionate preference for certainty" in intertemporal choice, indicating that different utility functions govern choices under certainty as distinct from risk. Support for this is derived from a time preference experiment using a "Convex Time Budget" (CTB) design (Andreoni and Sprenger, 2012a) in which subjects allocate an endowment of tokens between two dates, with tokens allocated to the sooner date yielding a smaller return than ones allocated to the later date. ${ }^{2}$ In their main manipulation, A\&S compare decisions in which payments on both dates are certain to ones in which both payments are received with $50 \%$ probability, as realized by two independent lotteries. They find that in the risky condition, subjects choose more balanced portfolios of sooner and later payments (A\&S, Figure 2), consistent with their interpretation that these choices are governed by a (atemporal) utility function that is more concave than that which applies under conditions of certainty. ${ }^{3}$

The proposition that different utility functions might apply under certainty as distinct from risk has immediate implications for established procedures to correct for utility curvature in estimating discount rates. In particular, an influential paper by Andersen et al. (2008, hereinafter AHLR) demonstrates that previous estimates of discount rates derived under the assumption of linear utility will be upwardly biased if utility is in fact concave. ${ }^{4}$ To correct for this bias, AHLR elicit utility curvature under conditions of risk, and combine this with discounting behavior elicited under conditions of certainty in a joint estimation procedure, finding that this results in substantially lower estimated discount rates. Their approach thus implicitly assumes that a single utility function governs choices in both sets of tasks. However if A\&S are correct that there are distinct utility functions under risk and certainty, joint estimation may itself result in misleading inferences. In particular, if the utility function were indeed more concave under risk then the AHLR procedure would overcorrect for utility curvature in discounting under certainty, resulting in an underestimate of the discount rate. To obtain an unbiased estimate, it would be necessary to combine discounting and curvature data obtained under comparable risk conditions.

In the experimental design of AHLR, both risk and time preferences are elicited using "Multiple Price List" (MPL) instruments, in which subjects make a series of binary choices. ${ }^{5}$ In particular,

\footnotetext{
${ }^{1}$ This early literature is thoroughly reviewed by Frederick et al. (2002).

${ }^{2}$ Harrison and Swarthout (2011) note that a version of this procedure was proposed by Cubitt and Read (2007).

${ }^{3} \mathrm{~A} \& \mathrm{~S}$ interpret their result as supporting a " $u$ - $v$ " preference model characterized by discontinuity at certainty. Appendix Table A2 in A\&S reports their structural estimates indicating that the " $v$ " function estimated under certainty is close to linear, whereas the " $u$ " function estimated under risk is substantially more concave.

${ }^{4}$ If utility is concave, both diminishing marginal utility and discounting for time delay will favor a smaller sooner payment. Therefore if the former is assumed away, then the effect of the latter will be overstated.

${ }^{5}$ The MPL design for risk preference is based upon Holt and Laury (2002), while the MPL design for time preference is due to Coller and Williams (1999). Although the Holt and Laury instrument is typically interpreted as a measure of risk preference, AHLR are not concerned with this per se but rather the implied curvature of the utility function.
} 
in each decision in a discounting MPL a subject chooses either to receive a smaller sooner or a larger later payment, whereas in a CTB decision it is possible to choose a mixture of the two. This distinction becomes critical when the element of risk is added to the payments. Since A\&S realize their sooner and later CTB payments using two independent lotteries, a subject could spread these risks by choosing a mixture of the two payments, whereas at a corner allocation payment depends only on a single lottery. Since this "intertemporal diversification" motive does not arise when both payments are certain, it might provide an alternative explanation for A\&S's finding of more balanced intertemporal portfolio allocations under risk as compared to certainty.

Motivated by these two observations - the first being an implication of A\&S's result for the joint estimation strategy of AHLR, and the second being a procedural aspect of the CTB design as applied to choices involving risk - in this comment I investigate the robustness of A\&S's result to two simple modifications of the experimental design. Firstly, in my MPL experiment I replicate the design and estimation procedures of AHLR, adding a set of discounting MPLs in which payments are received with $50 \%$ probability. With this data, I can compare the results of joint estimation when both utility curvature and discounting are elicited under risk to when the latter is elicited under certainty as in AHLR, and thus evaluate the magnitude of any bias in the joint estimation procedure. Moreover, this experiment embeds a replication of the main $(1,1)$ versus $(0.5,0.5)$ manipulation in $\mathrm{A} \& \mathrm{~S}$ in which the CTB is replaced by an MPL. Secondly, in my CTB experiment I replicate the design and estimation procedures of A\&S, adding a set of CTBs in which both payments are received with $50 \%$ probability as realized by a single lottery. In this condition the sooner and later payment risks are perfectly correlated, and by comparing it to a corresponding independent lotteries condition I can assess what portion of A\&S's result is driven by diversification behavior.

In my MPL data, I find almost no evidence of differences in intertemporal choice behavior under conditions of risk as compared to certainty. As a result, the riskiness of payments has a negligible effect upon the results of the AHLR joint estimation procedure. One reason for this could be that the MPL instrument might simply be too blunt to detect differences in preferences that express themselves as shifts in interior solutions in a CTB. However, another potential explanation is that the binary choice nature of the MPL does not permit intertemporal diversification.

The results of my CTB experiment indicate that both factors are likely to be at work. In the correlated risks condition - in which payments are subject to risk but diversification is not possible - the difference in behavior relative to certainty is reduced by just over one-half when compared to the independent risks condition. However it appears that all three risk conditions are distinct, and differ significantly from one another. Thus the effect reported by A\&S is substantially diminished when the possibility of diversification is removed, but nonetheless persists.

Just as the standard model of discounted expected utility (DEU) cannot explain A\&S's original finding of a difference between certainty and independent risks, it also cannot explain my finding of a difference between independent and correlated risks, since the standard model in fact predicts the same behavior in all three conditions. In particular, the linearity of the intertemporal utility function in the standard model implies that it does not predict intertemporal diversification. A 
simple extension to allow concavity of intertemporal utility - equivalent to the "correlation aversion" model recently estimated by Andersen et al. (2011) - generates a prediction of differential behavior under independent versus correlated risks. However even that model does not predict my evidence of a difference between certainty and correlated risks. ${ }^{6}$ This latter difference thus not only survives my scrutiny of the experimental design, but also remains open for interpretation.

The remainder of this comment is organized as follows. Section 1 presents the design and results of my MPL experiment, Section 2 presents the design and results of my CTB experiment, and Section 3 concludes. Statements of model predictions, detailed enumeration of parameters, and the full experimental instructions are provided in the appendices, available online.

\section{Multiple price list experiment}

\subsection{Design and procedures}

The design of my MPL experiment was based upon AHLR. Each subject completed four risk preference MPL tables to identify utility curvature, as well as eight time preference MPL tables, with a total of ten binary decision rows in each table. In four of the discounting tasks both the sooner and later payment options were certain, while the other four were identical except that both payment options were received with $50 \%$ probability. The risk preference and certain discounting components thus replicate the design of AHLR, while the certain and risky discounting components replicate the main conditions in A\&S using an MPL instrument instead of a CTB. In particular, the standard DEU model predicts the same pattern of choices under both the certain and risky discounting conditions, just as it does in the CTB design of A\&S (see Appendix A for details).

The payoffs in the risk preference tasks were chosen to span a similar range as the time preference tasks, and thus measure curvature over the relevant region of the utility function. In the discounting tasks, the sooner payment option always carried a front-end delay of one week while the later payment option was delayed by a further three, six, nine, or twelve weeks. ${ }^{7}$ All payment dates thus fell on the same weekday as the experiment itself, and were also designed to fall within teaching weeks of the current semester, avoiding holidays.

Each subject was paid for one randomly-chosen risk preference decision, received in cash before leaving the laboratory. Each subject also had one time preference decision randomly chosen to count for payment. If this decision was one that involved risk, the lottery to determine whether or not the payment option chosen by the subject would in fact be sent was also realized before leaving the laboratory. However the actual payment, being delayed, was made by check, drawn on the campus branch of the National Australia Bank and mailed by Australia Post guaranteed Express Post. ${ }^{8}$

\footnotetext{
${ }^{6}$ Formal statements of these implications of the two models are set out in Appendix A.

${ }^{7}$ Full details of the parameters of the MPL decisions are provided in Appendix B.1. In the three and nine week discounting horizons, the smaller sooner payment option was fixed and the larger later option varied, consistent with the design of AHLR. In the six and twelve week horizons, the larger later option was fixed and the smaller sooner option varied, consistent with the design of A\&S.

${ }^{8}$ Australia Post guarantees next-day delivery for articles mailed by Express Post, at a cost of approximately AUD 5 per envelope. The procedures also incorporated several other measures adopted by Andreoni and Sprenger
} 
A total of 81 student subjects completed the MPL experiment at an Australian research university on 26 and 27 July 2011. The realized average payments were AUD 19 for the risk preference component, and AUD 21 for the time preference component. ${ }^{9}$ The experiment was conducted using pen and paper, and took approximately 90 minutes to complete. ${ }^{10}$

\subsection{Results of the MPL experiment}

Figure 1 summarizes aggregate discounting behavior in the MPL experiment, with each panel corresponding to a different delay length between the sooner and later payment options. In each panel, the percentage of subjects who chose the sooner option in each decision is plotted against the gross experimental interest rate (i.e. the ratio of the values of the later to the sooner payment options), with the confidence bars representing the normal approximation to the $95 \%$ confidence interval for a binomial proportion. This presentation thus mirrors that of Figure 2 in A\&S.

In contrast to A\&S's results using a CTB instrument, Figure 1 clearly shows that in my MPL data there is very little evidence of any systematic deviations in discounting behavior under risk as compared to certainty. In particular, out of 40 possible pairwise comparisons, there are no cases in which the proportion of sooner choices in the certain condition falls outside of the $95 \%$ confidence interval for the risky condition, and only three cases in which the converse holds. ${ }^{11}$ In short, the effect reported by A\&S largely disappears when an MPL design is used in place of their CTB.

Recall that the MPL experiment was motivated by the possibility that differences in preferences under risk versus certainty might cause the estimation procedures developed by AHLR for MPL data to be biased. To examine this possibility, I replicate their estimates using my MPL data and report the results in Table 1. In particular, I adopt the same structural model and notation as Appendix A.1.1 in A\&S, who assume an exponentially-discounted CRRA utility function:

$$
U=\delta^{t}\left(c_{t}-\omega\right)^{\alpha}+\delta^{t+k}\left(c_{t+k}-\omega\right)^{\alpha}
$$

where $t$ is the front-end delay in days to the sooner payment option, $k$ is the additional delay to the later option, $c$ denotes experimental earnings and $\omega$ is a "background" parameter. ${ }^{12}$ The parameter $\alpha$ measures utility curvature such that $(1-\alpha)$ is the coefficient of relative risk aversion, and $\delta$ is the daily exponential discount factor such that $\rho \equiv 1 / \delta^{365}-1$ is the implied (net) annual discount rate. A\&S impose an exponential discount function because analysis of quasi-hyperbolic discounting is precluded by the fact that all sooner payments carry a front-end delay. However, as I emphasize in

(2012a) to minimize the background risk associated with future payments. In particular, subjects addressed their own envelopes, wrote their own payment amounts and dates inside their envelopes, and were given the business card of the experimenter to contact in the event of a payment not arriving as expected.

${ }^{9}$ At the time of the MPL experiment, one AUD was worth approximately USD 1.10 .

${ }^{10}$ The full text of the instructions for the MPL experiment are provided in Appendix C. The risk preference tasks were always completed first, and half of the subjects completed the discounting tasks under certainty before discounting under risk while for the other half this order was reversed. There was no evidence of any order effect.

${ }^{11}$ These correspond to the gross interest rates of 1.45 and 1.5 in the three-week horizon, and the gross interest rate of 1.4 in the nine-week horizon. However, as can be seen in Figure 1, even these differences are slight.

${ }^{12}$ If $\omega$ is positive, it may be interpreted as a Stone-Geary minimum or reference point. If it is negative, $B \equiv-\omega$ may be interpreted as background consumption. 
Figure 1: Aggregate Behavior in MPL Discounting Tasks.
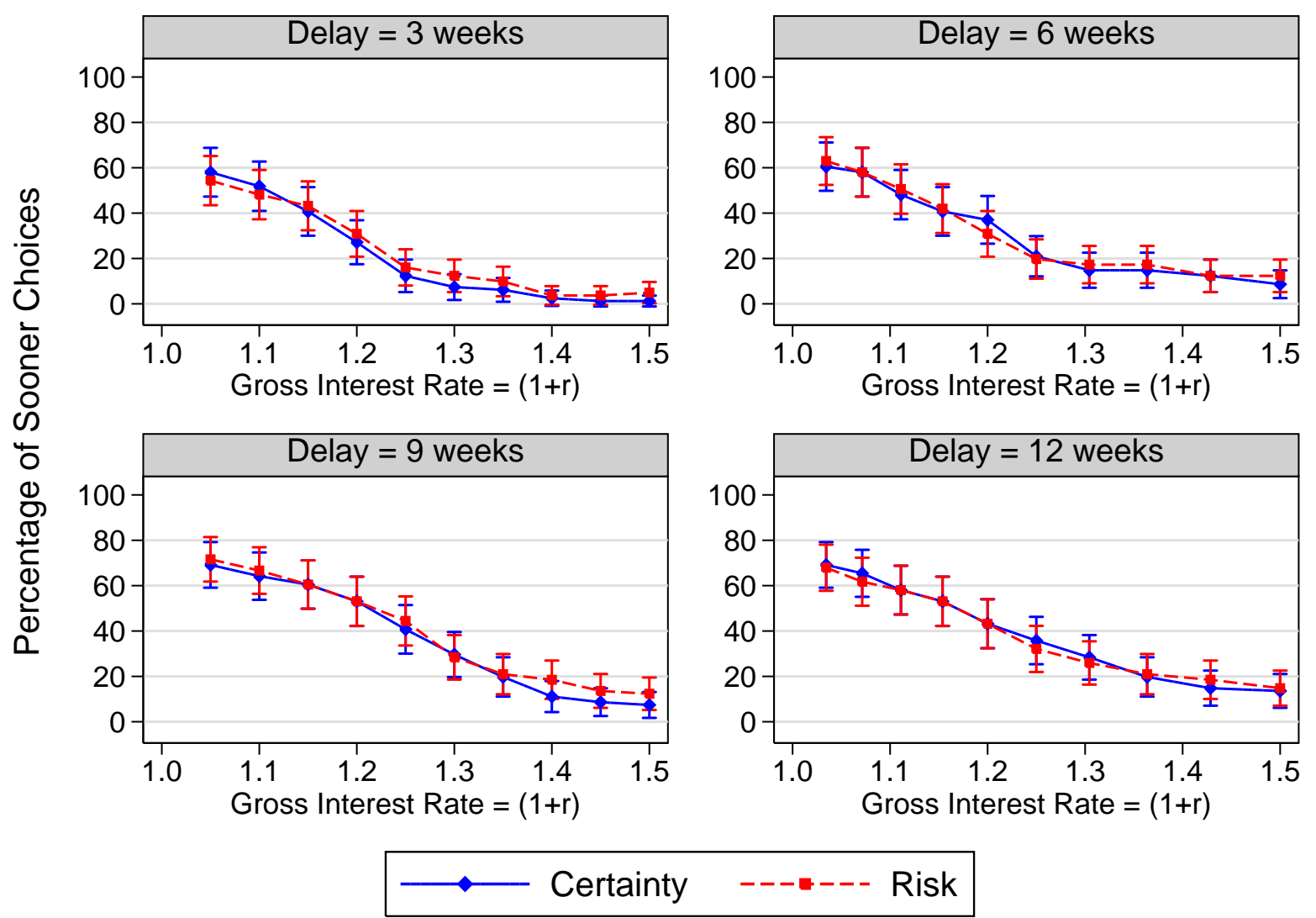

stating model predictions in Appendix A, the specification of the discount function is not germane to the core issue of differential behavior under risk versus certainty.

Model (1) in Table 1 reports estimates of the annual discount rate using data from the time preference tasks only and assuming linear utility. Model (2) reports joint estimates of utility curvature and discounting using data from both the risk and time preference tasks and allowing for a concave utility function. In each model, the estimate of the annual discount rate $\rho$ is permitted to differ between the discounting tasks elicited under certainty as compared to risk.

In particular, the joint estimate of $\rho_{\text {Cert }}$ in model (2) combines utility curvature elicited under risk with discounting elicited under certainty, and corresponds to the original estimation procedure in AHLR. This estimate is potentially misspecified if those choices are governed by distinct utility functions. By contrast, the joint estimate of $\rho_{\text {Risk }}$ is estimated from discounting choices under risk and as a result it is robust to this form of misspecification. The models were estimated by maximum likelihood in Stata 10.1, following the procedures set out in AHLR, with robust standard errors clustered on individual subjects. ${ }^{13}$

\footnotetext{
${ }^{13}$ In the models in Table 1 , the value of the background parameter is set to $\omega=0$. The parameters $\mu$ and $\nu$ are structural "noise" terms to model decision errors in the curvature and discounting choices respectively, and moreover the estimate of $\nu$ is also permitted to differ between the discounting tasks elicited under risk and certainty.
} 
Table 1: Estimates of Utility Curvature and Annual Discount Rates from MPL Data.

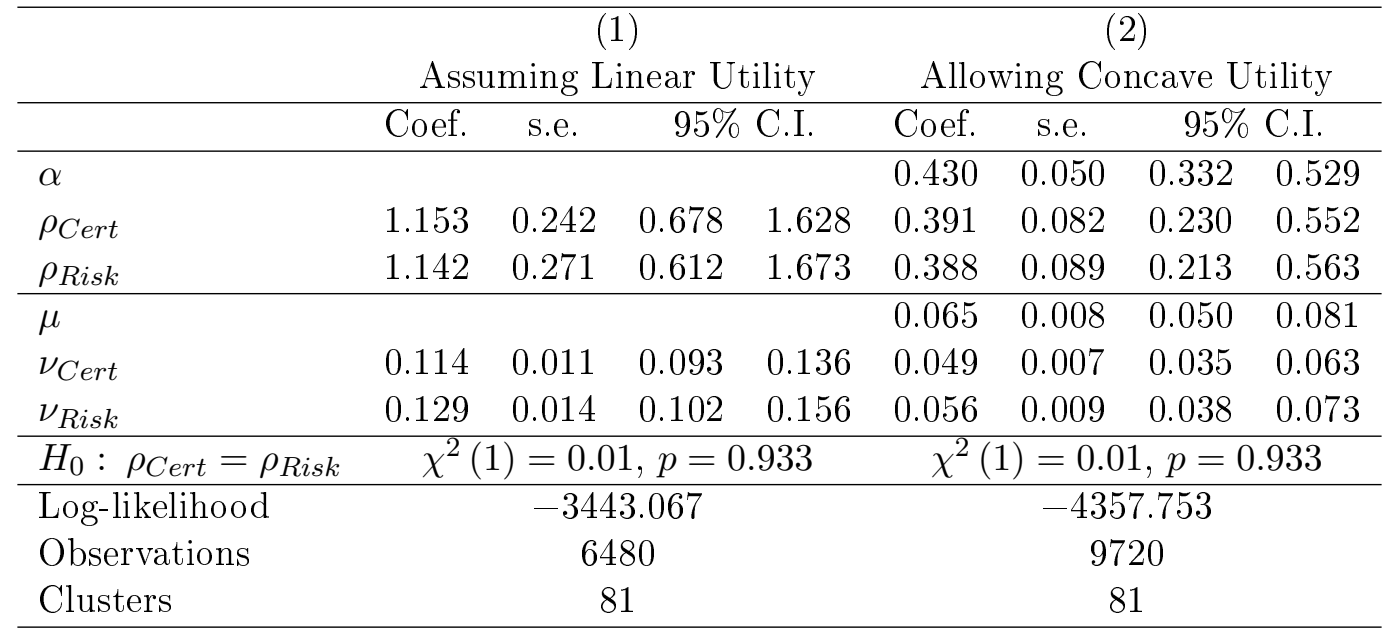

Notes: ML estimates with the restriction $\omega=0$. The structural "noise" parameters $\mu$ and $\nu$ model decision errors in the curvature and discounting choices respectively. Robust standard errors are clustered at the level of individual subjects.

In model (1) of Table 1, which does not correct for curvature of the utility function, the annual discount rate is estimated at $115.3 \%$ when payments are certain and $114.2 \%$ when they are received with $50 \%$ probability. The difference between these estimates is clearly not statistically significant $(p=0.933)$. This confirms what was already apparent from Figure 1, namely that in the MPL data discounting behavior under the two risk conditions is virtually indistinguishable.

In model (2), the estimate of the utility curvature parameter $\alpha$ is 0.430 , implying a coefficient of relative risk aversion of 0.570 . Correcting for this curvature in joint estimation lowers the estimated annual discount rate to $39.1 \%$ under certainty and $38.8 \%$ under risk. These estimates are clearly very close, and the difference between them is both inconsequential compared to the effect of correcting for curvature relative to the estimates in model (1) and clearly not statistically significant $(p=0.933)$. This establishes the main result from the MPL experiment, namely that the possibility that distinct utility functions might govern discounting under risk versus certainty does not appear to bias the results of the AHLR joint estimation procedure for estimating discount rates from MPL data.

The finding that discounting behavior does not differ under risk versus certainty in an MPL experiment is consistent with the standard DEU model. However, given that A\&S do not obtain the same result in their CTB design, it cannot necessarily be taken as an endorsement of that model. In particular, the binary choice nature of the MPL may be both a blessing and a curse. On the one hand, one reason why no effect is observed could simply be that the MPL instrument may be too blunt to pick up differences in preferences that are detected by a CTB. On the other hand, since risky choices in an MPL only ever result in a single payment determined by a single lottery, the possibility of intertemporal diversification is also precluded. The purpose of my CTB experiment is 
to disentangle these two explanations for why A\&S's effect is not observed in my MPL data.

\section{Convex time budget experiment}

\subsection{Design and procedures}

The design of my CTB experiment was based closely upon that of A\&S. In each CTB decision, a subject had an endowment of 100 tokens which they were free to allocate as they pleased between the sooner and later payment dates at specified exchange rates. Across all decisions, the exchange rate for tokens redeemed on the later payment date was fixed, while the sooner token exchange rate was manipulated to generate variation in the gross experimental interest rate. Each subject made a total of 42 such decisions, comprising seven gross interest rates crossed with two delay lengths, all repeated under three different risk conditions.

In the certainty condition the payments on both dates would be sent for sure, while in the independent risks condition both payments would be sent with $50 \%$ probability, as realized by two independent lotteries. These conditions thus replicate the $(1,1)$ and $(0.5,0.5)$ conditions in A\&S. Finally, in the correlated risks condition both payments would be sent with $50 \%$ probability, as realized by a single lottery. Thus in this condition it was not possible for a subject to spread their risks over two lotteries by choosing a mixture of sooner and later payments. A\&S show that the standard DEU model predicts the same pattern of choices under certainty and independent risks; moreover it turns out that the same holds for correlated risks as well (see Appendix A for details).

The parameters of the CTB experiment were identical to those of A\&S Table 1, except that the delay lengths between sooner and later payments were changed from four and eight weeks in A\&S to five and ten weeks, and payments were denominated in AUD instead of USD. ${ }^{14}$ The sooner payment always carried a one-week front-end delay, and all payment dates fell on the same weekday as the experiment itself, within teaching weeks of the current semester, and avoiding holidays. The decision tables for the experiment replicated the format adopted by A\&S, with the addition of a background color-shading convention to distinguish between the three risk conditions. ${ }^{15}$

Each subject had one CTB decision randomly chosen to count for pay. If this decision was one involving risk, then the lottery or lotteries to determine whether or not the chosen payments would in fact be sent were realized before leaving the laboratory. Both the sooner and later payments were made by check, drawn on the campus branch of the National Australia Bank, and mailed by guaranteed next-day Express Post. Following A\&S's procedures, each subject received a show-up fee

\footnotetext{
${ }^{14}$ Full details of the parameters of the CTB decisions are provided in Appendix B.2. The reason for the change in delay lengths was to avoid having one of the payment dates falling adjacent to a public holiday.

${ }^{15}$ As per A\&S, subjects were provided with a calendar on the left-hand side of each table with the date of the experiment and the sooner and later payment dates highlighted. In addition, in the independent risks condition the columns corresponding to the sooner and later token allocations were shaded in two different colors to represent the colors of the two separate die that would be rolled to determine the payments. In the correlated risks condition, both columns were shaded alike to indicate that a single die roll would determine both payments. Finally, in the certainty condition both columns were unshaded to indicate that the payments would not depend upon any die roll at all. Appendix E shows a sample decision sheet from the independent risks condition.
} 
comprising two payments of AUD 5 each, sent on the sooner and later payment dates respectively, with any additional earnings from the experiment added to these. Since this implied that every subject would always receive two checks, it ensured that there was no convenience benefit to choosing a corner allocation accruing entirely on a single payment date. Since every subject addressed their own envelopes prior to making their decisions, they could observe that the experimenter was prepared to pay approximately AUD 5 to mail a check to the value of as little as AUD 5 by Express Post. This imparted a high level of credibility to the payments. ${ }^{16}$

A total of 63 student subjects completed the CTB experiment on 20 and 22 March 2012. The realized average payment was AUD 24 inclusive of the show-up fee. ${ }^{17}$ The experiment was conducted using pen and paper, and took approximately 60 minutes to complete. ${ }^{18}$

\subsection{Results of the CTB experiment}

Figure 2 summarizes aggregate behavior in the CTB experiment, with each panel corresponding to a different delay length, using the same presentation as Figure 2 in A\&S. The mean allocation of tokens (out of 100) to the sooner payment date is plotted as a function of the gross interest rate (i.e. the ratio of the values of the later to the sooner token redemption values) for each risk condition, together with the corresponding $95 \%$ ( \pm 1.96 s.e.) confidence intervals. The mean allocations are also reported in tabular form on the left-hand side of Table 2, in which the right-hand columns report $p$-values for Wilcoxon signed-ranks tests of equality of token allocations in each pairwise comparison of risk conditions, at each delay and gross interest rate combination. The patterns that emerge from close inspection of Figure 2 and from the signed-ranks tests are very similar, and in the discussion that follows I use the latter as the preferred basis for comparison since they avoid distributional assumptions and recognize the within-subjects nature of the data.

The first important result that is apparent is that choices under certainty and independent risks replicate the pattern observed by $\mathrm{A} \& \mathrm{~S}$ in their $(1,1)$ and $(0.5,0.5)$ conditions: the mean token allocation between sooner and later payments is consistently more balanced under independent risks compared to certainty. The differences between these two conditions are always highly significant, except at the gross interest rate of 1.05 where the two functions "cross over".

This pattern is inconsistent with the standard DEU model; however behavior under independent risks may also reflect a diversification motive that is absent when all payments are certain. The correlated risks condition eliminates this possibility of diversification while retaining the feature of riskiness of payments. If A\&S's result were robust to removing opportunities for diversification then behavior under correlated risks would coincide with that under independent risks. On the other hand, if their result were driven entirely by diversification then it would disappear under correlated

\footnotetext{
${ }^{16}$ In the post-experiment questionnaire for the CTB experiment, $100 \%$ of subjects responded that they trusted that they would be paid exactly as stated in the instructions.

${ }^{17}$ At the time of the CTB experiment, one AUD was worth approximately USD 1.05 .

${ }^{18}$ The full text of the instructions for the CTB experiment are provided in Appendix D. Subjects who participated in the earlier MPL experiment were excluded from the CTB study. Half of the subjects completed the risk conditions in the order independent-certain-correlated, while for the other half this was reversed.
} 
Figure 2: Aggregate Behavior in CTB Discounting Tasks.
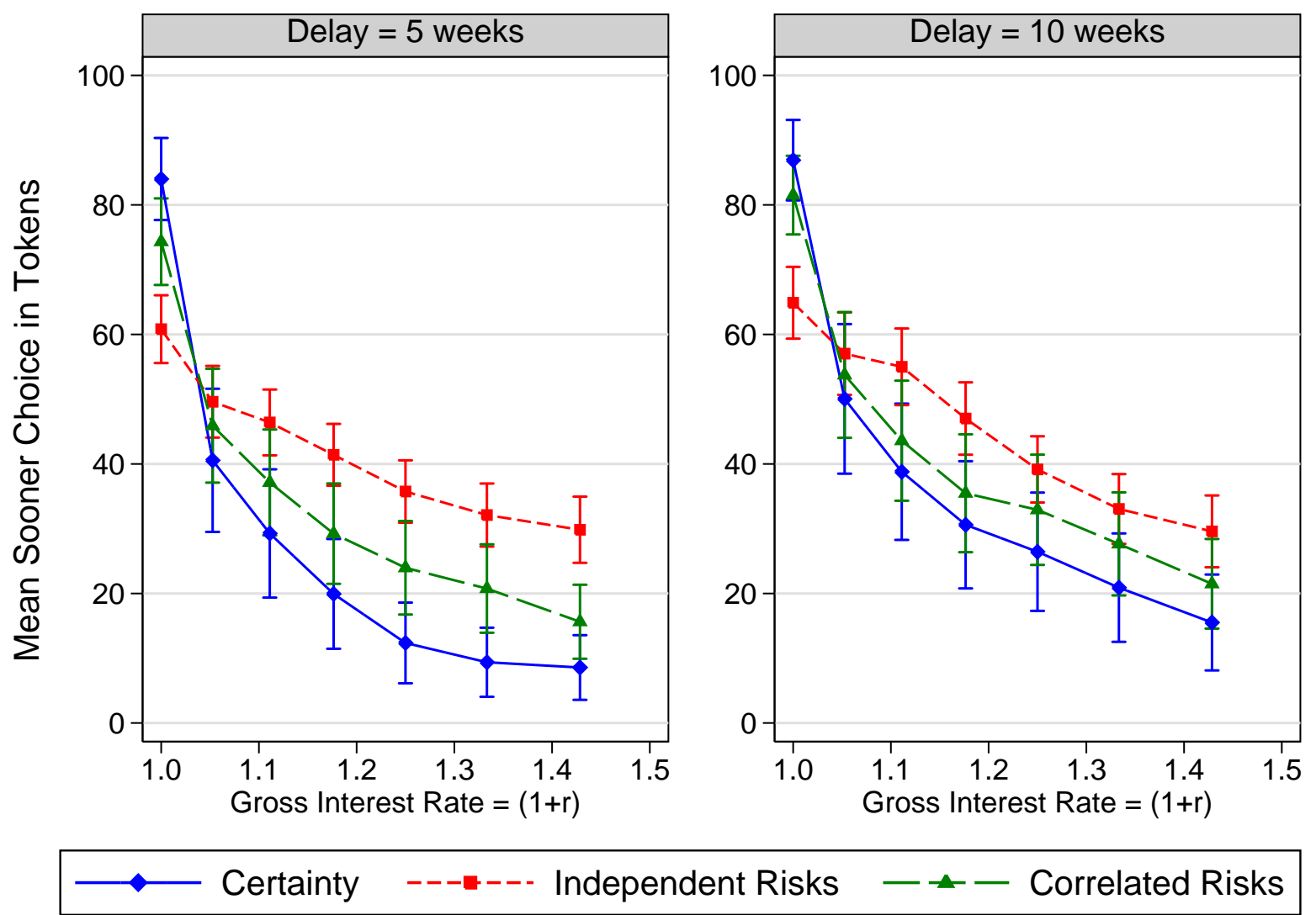

risks, such that behavior would coincide with that under certainty.

Figure 2 reveals that behavior under correlated risks is in fact clearly intermediate between certainty and independent risks. Moreover, the test statistics reported in Table 2 indicate that the differences in choices between all three risk conditions are generally significant. This is especially the case in the five-week delay horizon, in which they are consistently significant except at the gross interest rate of 1.05; in the ten-week horizon the differences become somewhat narrower, especially in the comparison between certainty and correlated risks.

For each pairwise comparison of risk conditions, I next follow A\&S in performing non-parametric OLS regressions of sooner token allocations on indicators for each delay length and gross interest rate combination interacted with the risk condition, with standard errors clustered on individual subjects, and test for the joint significance of all treatment interactions. The results confirm that all three risk conditions are distinct, with all differences found to be highly significant. ${ }^{19}$

Direct evidence that behavior under independent risks is likely motivated in part by diversifi-

\footnotetext{
${ }^{19}$ For the comparison of certainty to independent risks, $F_{14,62}=11.04, p<0.001$. For certainty and correlated risks, $F_{14,62}=2.29, p=0.013$. For independent and correlated risks, $F_{14,62}=5.13, p<0.001$. When the tenweek horizon is considered in isolation, the difference between certainty and correlated risks ceases to be significant: $F_{7,62}=1.65, p=0.137$. However all other comparisons are highly significant in both the five and ten-week horizons.
} 
Table 2: Tests of Equality of Allocations in the CTB Experiment.

\begin{tabular}{ccccccc}
\hline \multirow{2}{*}{ Gross Rate } & \multicolumn{3}{c}{ Mean Sooner Token Allocation } & \multicolumn{3}{c}{ Wilcoxon signed-ranks $p$-values } \\
& Certain & Independent & Correlated & Cert $=$ Ind & Cert $=$ Corr & Ind $=$ Corr \\
\hline 1.00 & 84.0 & 60.8 & 74.3 & 0.000 & 0.003 & 0.000 \\
1.05 & 40.6 & 49.6 & 45.9 & 0.067 & 0.191 & 0.266 \\
1.11 & 29.3 & 46.4 & 37.1 & 0.001 & 0.076 & 0.015 \\
1.18 & 19.9 & 41.4 & 29.2 & 0.000 & 0.038 & 0.000 \\
1.25 & 12.4 & 35.7 & 24.0 & 0.000 & 0.006 & 0.001 \\
1.33 & 9.4 & 32.1 & 20.8 & 0.000 & 0.001 & 0.000 \\
1.43 & 8.6 & 29.8 & 15.6 & 0.000 & 0.009 & 0.000 \\
\hline & & \multicolumn{5}{c}{ A. Delay $=5$ weeks } \\
\hline 1.00 & 86.9 & 64.9 & 81.5 & 0.000 & 0.010 & 0.000 \\
1.05 & 50.0 & 57.0 & 53.7 & 0.117 & 0.508 & 0.436 \\
1.11 & 38.8 & 55.0 & 43.6 & 0.001 & 0.248 & 0.008 \\
1.18 & 30.6 & 47.0 & 35.5 & 0.000 & 0.130 & 0.007 \\
1.25 & 26.4 & 39.2 & 32.9 & 0.001 & 0.077 & 0.064 \\
1.33 & 20.9 & 33.0 & 27.7 & 0.003 & 0.040 & 0.134 \\
1.43 & 15.5 & 29.6 & 21.5 & 0.001 & 0.038 & 0.038 \\
\hline
\end{tabular}

cation may be seen by comparing the incidence of corner solutions across risk conditions. Under certainty corner solutions are endemic, accounting for in excess of $70 \%$ of all CTB allocations $(19.8 \%$ all sooner and $52.4 \%$ all later). Under independent risks - where diversification favors the choice of an interior solution - corner allocations are far less prevalent ( $5.1 \%$ and $11.6 \%$ respectively). Under correlated risks, corner solutions are three times as prevalent as under independent risks $(14.9 \%$ and $35.6 \%$ respectively) although still fewer than under certainty.

Figure 3 reports an analysis of two measures of the consistency of choices at an individual level following the presentation of A\&S Figure 3. The top panel relates to the comparison between certainty and independent risks, while the bottom panel compares certainty to correlated risks. For each subject, I compute the number of occasions out of fourteen in which that subject made inconsistent choices between two risk conditions, as well as that subject's average absolute difference in tokens allocated to the sooner payment across those fourteen comparisons, and present histograms of these measures in Figure 3. The comparison between certainty and independent risks closely replicates the corresponding analysis in A\&S Figure 3, Panel A. Turning to the comparison between certainty and correlated risks, there is a clear shift in the direction of fewer and smaller deviations in choice behavior, however these differences also clearly do not go away completely.

Averaging over all decisions by all subjects, the mean absolute difference in allocations between certainty and independent risks is 29.65 tokens $(s . d .=15.18)$; between certainty and correlated risks it is 14.75 tokens $(s . d .=14.91$ ). Thus overall, the effect reported by A\&S is reduced by slightly over one-half when the opportunity for diversification is taken away. This is the main aggregate conclusion to emerge from my CTB experiment. 
Figure 3: Individual Behavior in the CTB Experiment.

\section{A. Certainty vs. Independent Risks}
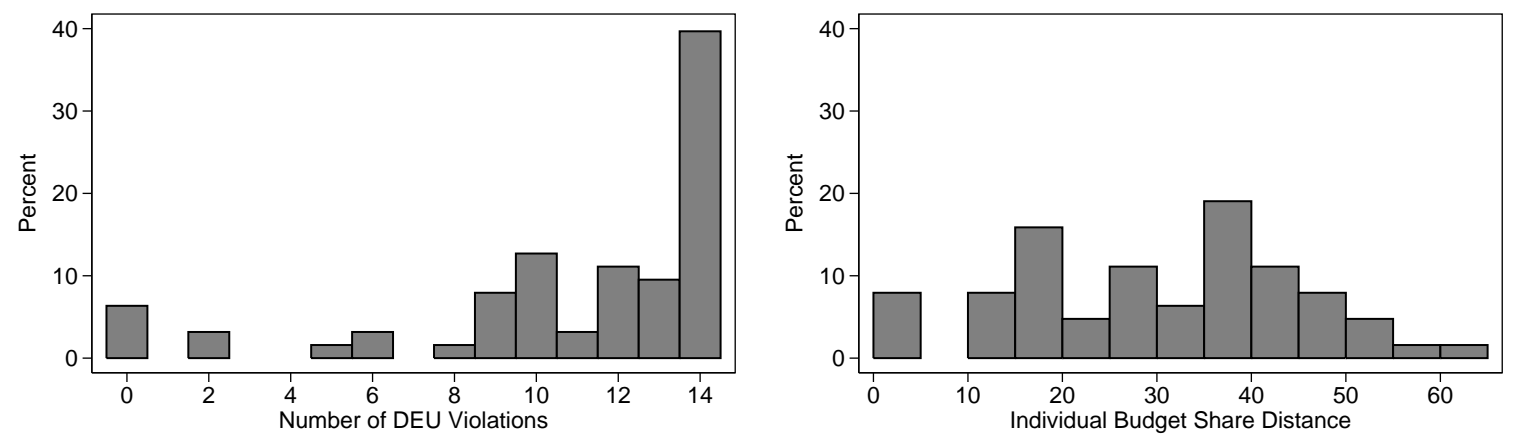

\section{B. Certainty vs. Correlated Risks}
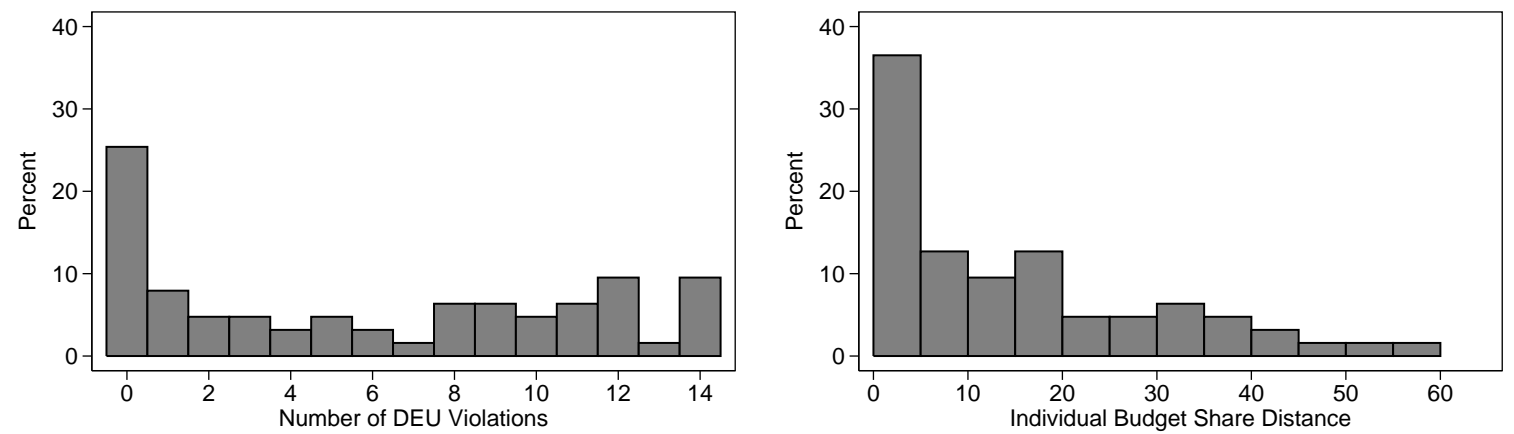

How do these results affect the structural estimates of utility curvature and discount rates estimated from CTB data? A\&S Appendix A.1.1 report non-linear least squares (NLS) estimates in which the structural parameters are permitted to differ across their $(1,1)$ and $(0.5,0.5)$ risk conditions. Their results indicate that the curvature estimates differ significantly between risk conditions but that discount rates do not, and they interpret the separate curvature parameters to represent two distinct utility functions: $v(\cdot)$ under certainty and $u(\cdot)$ under risk.

In Table 3, I replicate A\&S's estimation procedures using data from my CTB experiment. The top panel reports estimates of utility curvature $\alpha$ and the annual discount rate $\rho$, which are permitted to vary across the three risk conditions. The bottom panel reports hypothesis tests of both pairwise and joint equality of these parameters across risk conditions. In model (1) the "background" term $\omega$ is estimated as a parameter, which is also permitted to vary across risk conditions (as per the CTB estimates of A\&S). In model (2) $\omega$ is set to zero (as per my MPL estimates in Table 1). The models were estimated by NLS in Stata 10.1, following the procedures set out in Andreoni and Sprenger (2012a) and A\&S Appendix A.1.1, with robust standard errors clustered on individual subjects.

The results in Table 3 display an interesting pattern that is also evident in the results reported by A\&S: in the structural estimates, the differences in behavior across the three risk conditions 
Table 3: Estimates of Utility Curvature and Annual Discount Rates from CTB Data.

\begin{tabular}{|c|c|c|c|c|c|c|c|}
\hline & \multicolumn{3}{|c|}{$(1)$} & \multicolumn{4}{|c|}{$(2)$} \\
\hline \multicolumn{8}{|c|}{ A. Parameter Estimates } \\
\hline & Coef. & s.e. & 95\% C.I. & Coef. & s.e. & $95 \%$ & C.I. \\
\hline$\omega_{\text {Cert }}$ & 2.331 & 0.466 & $1.400 \quad 3.261$ & & & & \\
\hline$\omega_{\text {Ind }}$ & 3.196 & 0.540 & 2.116 & & & & \\
\hline$\omega_{\text {Corr }}$ & 3.180 & 0.458 & 2.265 & & & & \\
\hline$\alpha_{\text {Cert }}$ & 0.963 & 0.004 & 0.955 & 0.924 & 0.008 & 0.908 & 0.941 \\
\hline$\alpha_{\text {Ind }}$ & 0.883 & 0.020 & 0.844 & 0.796 & 0.022 & 0.751 & 0.841 \\
\hline$\alpha_{\text {Corr }}$ & 0.948 & 0.006 & 0.937 & 0.883 & 0.013 & 0.857 & 0.908 \\
\hline$\rho_{\text {Cert }}$ & 0.499 & 0.103 & 0.292 & 0.592 & 0.133 & 0.326 & 0.858 \\
\hline$\rho_{\text {Ind }}$ & 0.762 & 0.178 & 1.118 & 0.787 & 0.190 & 0.407 & 1.167 \\
\hline$\rho_{\text {Corr }}$ & 0.600 & 0.130 & $0.341 \quad 0.859$ & 0.705 & 0.165 & 0.376 & 1.034 \\
\hline \multicolumn{8}{|c|}{ B. Hypothesis Tests for Equality of Parameters across Risk Conditions } \\
\hline$\alpha_{\text {Cert }}=\alpha_{\text {Ind }}$ & \multicolumn{3}{|c|}{$F_{1,62}=16.67, p<0.001$} & \multicolumn{4}{|c|}{$F_{1,62}=34.61, p<0.001$} \\
\hline$\alpha_{\text {Cert }}=\alpha_{\text {Corr }}$ & \multicolumn{3}{|c|}{$F_{1,62}=10.03, p=0.002$} & \multicolumn{4}{|c|}{$F_{1,62}=17.77, p<0.001$} \\
\hline$\alpha_{\text {Ind }}=\alpha_{\text {Corr }}$ & \multicolumn{3}{|c|}{$F_{1,62}=10.53, p=0.002$} & \multicolumn{4}{|c|}{$F_{1,62}=15.17, p<0.001$} \\
\hline$\alpha_{\text {Cert }}=\alpha_{\text {Ind }}=\alpha_{\text {Corr }}$ & \multicolumn{3}{|c|}{$F_{2,62}=13.69, p<0.001$} & \multicolumn{4}{|c|}{$F_{2,62}=22.37, p<0.001$} \\
\hline$\rho_{\text {Cert }}=\rho_{\text {Ind }}$ & \multicolumn{3}{|c|}{$F_{1,62}=3.08, p=0.084$} & \multicolumn{4}{|c|}{$F_{1,62}=1.50, p=0.226$} \\
\hline$\rho_{\text {Cert }}=\rho_{\text {Corr }}$ & \multicolumn{3}{|c|}{$F_{1,62}=2.16, p=0.147$} & \multicolumn{4}{|c|}{$F_{1,62}=1.70, p=0.197$} \\
\hline$\rho_{\text {Ind }}=\rho_{\text {Corr }}$ & \multicolumn{3}{|c|}{$F_{1,62}=1.20, p=0.278$} & \multicolumn{4}{|c|}{$F_{1,62}=0.26, p=0.611$} \\
\hline$\rho_{\text {Cert }}=\rho_{\text {Ind }}=\rho_{\text {Corr }}$ & \multicolumn{3}{|c|}{$F_{2,62}=2.09, p=0.132$} & \multicolumn{4}{|c|}{$F_{2,62}=1.27, p=0.289$} \\
\hline$R^{2}$ & \multicolumn{3}{|c|}{0.703} & \multicolumn{4}{|c|}{0.697} \\
\hline Observations & \multicolumn{3}{|c|}{2646} & \multicolumn{4}{|c|}{2646} \\
\hline Clusters & \multicolumn{3}{|c|}{63} & \multicolumn{4}{|c|}{63} \\
\hline
\end{tabular}

Notes: Model (1): estimates with $\omega$ estimated as a parameter, separately for each risk condition (the hypothesis of equality of $\omega$ across the three risk conditions is rejected, with $F_{2,62}=3.39$ and $p=0.040$ ). Model (2): estimates with the restriction $\omega=0$. Models estimated by NLS with robust standard errors on individual subjects.

express themselves as differences in utility curvature but not in estimated discount rates. Across both specifications, the differences in estimated curvature parameters are always highly significant in both pairwise and joint tests; by contrast, the corresponding differences in estimated discount rates are consistently not statistically significant. It is therefore not possible to reject the null hypothesis that a single discount function governs intertemporal choices across all three risk conditions. ${ }^{20}$

\subsection{Discussion}

In the standard DEU model of equation (1), and in A\&S's interpretation of their results, differences in behavior under risk compared to certainty are attributed to differences in the concavity

\footnotetext{
${ }^{20}$ The same conclusion is also established when tests are performed directly on the estimates of the daily discount factor $\delta$ as opposed to the implied annual discount rate $\rho$.
} 
of atemporal utility as captured by the parameter $\alpha$. This form of concavity suffices to generate diversification in a familiar static setting in which a decision-maker is exposed to two risks that arise simultaneously. However, as discussed in Appendix A, it does not generate intertemporal diversification across risks that accrue on different dates, since the linearity of intertemporal utility under standard DEU implies that the same behavior is predicted under all three of my risk conditions.

Since intertemporal diversification does indeed appear to be important under independent risks - as evident from the far greater prevalence of interior solutions - it seems more appropriate to attribute behavior under independent risks to concavity of intertemporal utility. A simple specification that captures this is to replace (1) with:

$$
U=\left[\delta^{t}\left(c_{t}-\omega\right)^{\alpha}+\delta^{t+k}\left(c_{t+k}-\omega\right)^{\alpha}\right]^{\gamma}
$$

where the parameter $\gamma$ captures curvature of intertemporal utility such that $(1-\gamma)$ is a coefficient of relative intertemporal risk aversion or "correlation aversion" (Andersen et al., 2011; cf. their equation 12). Unfortunately, estimation of this model from CTB data is complicated by the fact that there does not appear to exist any closed form solution function under independent risks (Miao and Zhong, 2012). However, Andersen et al. (2011) have recently extended their MPL-based joint estimation methodology to include MPL tasks that elicit correlation aversion, permitting it to be jointly estimated with discounting and curvature of atemporal utility. They find that their subjects are indeed correlation averse, rejecting the specification in (1) in favor of the one in (2).

Finally, while the correlation aversion model predicts the difference I observe between independent and correlated risks, it does not explain the residual difference between certainty and correlated risks, since the model predicts the same behavior under these two conditions. This difference thus remains open for interpretation, with one candidate explanation being A\&S's conjecture that separate atemporal utility functions govern choices under the two conditions.

\section{Conclusion}

In this comment, I investigate the robustness of A\&S's finding of systematic differences in intertemporal choice behavior under risk versus certainty to two manipulations of their CTB design. Firstly, in principle A\&S's finding that utility is more concave under risk compared to certainty has the direct implication that joint estimates combining data generated from these two distinct preferences are potentially biased. In my MPL experiment I find very little support for this proposition, quite simply because I do not replicate A\&S's main result when using an MPL instrument.

Next, I examine the role of diversification opportunities in driving A\&S's finding of more balanced intertemporal portfolio choices under risk compared to certainty. I find that when the possibility of diversification is removed, while the element of risk is maintained, the effect observed by A\&S is reduced in magnitude by just over one-half. This result suggests a role for curvature of the intertemporal utility function, and not only of atemporal utility, in explaining intertemporal choice under risk - a conclusion that resonates with recent work by Andersen et al. (2011). 
My results shed new light on the relative merits of the MPL and CTB instruments, informing the design of future studies of time preference under conditions of risk. By permitting subjects to choose any point along a budget set instead of forcing them to choose between the endpoints, a CTB potentially provides richer information than an MPL. This may be why the CTB detects differences in choices between risk and certainty where an MPL does not. However, when implemented under risk, a CTB also potentially introduces opportunities for diversification where an MPL does not.

Finally, my finding of pronounced differences in behavior under independent versus correlated risks illustrates how procedural considerations such as the manner in which payments are realized are not merely arcane details of experimental design, but can exert a powerful influence on behavior - potentially to the point of driving a large portion of the observed effects. In this respect, my results also echo the important recent work of Cox et al. (2011). Moreover, they serve as a reminder that design choices that might appear innocuous under standard models such as DEU may in fact be highly consequential under alternative models such as correlation aversion. 


\section{References}

[1] Andersen, Steffen, Glenn W. Harrison, Morten I. Lau, and E. Elisabet Rutström. 2008. "Eliciting Risk and Time Preferences." Econometrica, 76(3): 583-618.

[2] Andersen, Steffen, Glenn W. Harrison, Morten I. Lau, and E. Elisabet Rutström. 2011. "Multiattribute Utility Theory, Intertemporal Utility and Correlation Aversion." Working paper 2011-04, Center for the Economic Analysis of Risk, Georgia State University.

[3] Andreoni, James, and Charles Sprenger. 2012a. "Estimating Time Preferences from Convex Budgets." American Economic Review, in press.

[4] Andreoni, James, and Charles Sprenger. 2012b. "Risk Preferences Are Not Time Preferences." American Economic Review, in press.

[5] Coller, Maribeth, and Melonie B. Williams. 1999. "Estimating Individual Discount Rates." Experimental Economics, 2(2): 107-27.

[6] Cox, James C., Vjollca Sadiraj, and Ulrich Schmidt. 2011. "Paradoxes and Mechanisms for Choice under Risk." Working paper 2011-07, Experimental Economics Center, Georgia State University.

[7] Cubitt, Robin P., and Daniel Read. 2007. "Can Intertemporal Choice Experiments Elicit Time Preferences for Consumption?" Experimental Economics, 10(4): 369-89.

[8] Frederick, Shane, George Loewenstein, and Ted O'Donoghue. 2002. "Time Discounting and Time Preference: A Critical Review." Journal of Economic Literature, 40(2): 351-401.

[9] Harrison, Glenn W., and J. Todd Swarthout. 2011. "Can Intertemporal Choice Experiments Elicit Time Preferences for Consumption? Yes." Working paper 2011-14, Center for the Economic Analysis of Risk, Georgia State University.

[10] Holt, Charles A., and Susan K. Laury. 2002. "Risk Aversion and Incentive Effects." American Economic Review, 92(5): 1644-55.

[11] Miao, Bin, and Songfa Zhong. 2012. "Separating Risk Preference and Time Preference." Working paper, National University of Singapore. 


\section{Appendices: Not for publication}

\section{A Model predictions}

\section{A.1 Predictions under discounted expected utility}

In this Appendix, I demonstrate that the standard model of discounted expected utility (DEU) predicts identical choices under each of the risk conditions for both of my experiments. I adopt a general specification of the discount function to emphasize that its particular functional form (for example, exponential or hyperbolic) is not germane to the issue of differential behavior under risk versus certainty. ${ }^{21}$ In keeping with my experimental design, I specialize to cases in which there are equal probabilities of payment on both the sooner and later payment dates.

\section{A.1.1 Multiple price list}

Let $u(\cdot)$ denote the (atemporal) utility function, and let $D(\cdot)$ denote the discount function. Consider two dates, $t$ and $t+k$, where $t$ denotes the front-end delay from the date of the experiment to the sooner payment date, and $k$ is the additional delay to the later payment date. Finally, let $B$ denote exogenous background consumption.

Consider the binary choice between Option A, which pays the exogenous amount $C_{t}$ (as specified by the experimenter) with probability $p$ on date $t$ (or zero otherwise), and Option B which pays $C_{t+k}$ with probability $p$ on date $t+k$. A subject prefers Option A (Option B) as:

$D(t)\left[p u\left(C_{t}+B\right)+(1-p) u(B)\right]+D(t+k) u(B) \gtrless D(t) u(B)+D(t+k)\left[p u\left(C_{t+k}+B\right)+(1-p) u(B)\right]$

or equivalently, as:

$$
D(t) p\left[u\left(C_{t}+B\right)-u(B)\right] \gtrless D(t+k) p\left[u\left(C_{t+k}+B\right)-u(B)\right]
$$

So long as the probability of payment $p$ is equal on both dates, this inequality does not depend upon the specific value of $p$, and in particular it remains unchanged when $p=1$ such that both payment options are certain. This is a restatement of the proposition that A\&S derive in the context of a CTB design (see Appendix A.1.2 below), as applied to the setting of an MPL.

\section{A.1.2 Convex time budget under independent risks}

In the independent risks version of the CTB design, there are two independent lotteries that determine whether or not payment is received on the sooner and later payment dates. A subject chooses the budget allocations $c_{t}$, to be received with probability $p$ on date $t$ (or zero otherwise), and $c_{t+k}$ to be received with probability $p$ on date $t+k$, to maximize:

\footnotetext{
${ }^{21} \mathrm{~A} \& \mathrm{~S}$ also present arguments for alternative specifications of the utility function that are equally applicable to the cases considered here.
} 


$$
D(t)\left[p u\left(c_{t}+B\right)+(1-p) u(B)\right]+D(t+k)\left[p u\left(c_{t+k}+B\right)+(1-p) u(B)\right]
$$

subject to the future value budget constraint:

$$
(1+r) c_{t}+c_{t+k}=m
$$

where $(1+r)$ is the gross experimental interest rate.

The "tangency condition" for an interior solution states that the ratio of discounted, expected, marginal utilities should equal the relative price ratio:

$$
\frac{D(t) p u^{\prime}\left(c_{t}+B\right)}{D(t+k) p u^{\prime}\left(c_{t+k}+B\right)}=(1+r)
$$

So long as the probability of payment $p$ is equal on both dates, this tangency condition does not depend upon the specific value of $p$, and in particular it remains unchanged when $p=1$ such that payments on both dates are certain. This is the proposition that A\&S set out to test in their main $(1,1)$ versus $(0.5,0.5)$ manipulation.

\section{A.1.3 Convex time budget under perfectly correlated risks}

In the correlated risks version of the CTB design, a single lottery determines whether or not payment is received on both the sooner and later payment dates. A subject chooses the budget allocations $c_{t}$ to be received on date $t$ and $c_{t+k}$ to be received on date $t+k$, where the entire portfolio is received with probability $p$ (or zero otherwise), to maximize:

$$
p\left[D(t) u\left(c_{t}+B\right)+D(t+k) u\left(c_{t+k}+B\right)\right]+(1-p)[D(t) u(B)+D(t+k) u(B)]
$$

Clearly, this expression is algebraically equivalent to (3), resulting in an equivalent tangency condition (and solution function) which again does not depend upon the value of $p$, and in particular remains unchanged when $p=1$ such that all payments are certain.

\section{A.2 Extension to a non-additive specification}

The standard DEU model thus predicts identical choices across all three risk conditions in my CTB experiment (certainty, independent risks, and correlated risks). Intuitively, in that model both discounting and expected utility are linear operators, and so it does not matter whether a subject maximizes discounted expected utility as in (3) or expected discounted utility as in (4). In particular, the model does not predict intertemporal diversification in the independent risks condition compared to the correlated risks condition in which diversification is not possible.

To generate such a prediction, it is necessary to break the nexus between (3) and (4) by introducing a non-additive specification. One simple way to do this has been explored by Andersen et al. (2011), who estimate such a model under specific functional form assumptions. For ease of notation, 
define $\xi\left(c_{t}, c_{t+k}\right) \equiv D(t) u\left(c_{t}\right)+D(t+k) u\left(c_{t+k}\right)$ and disregard background consumption from here on. Then the approach adopted by Andersen et al. embeds $\xi$ within a concave intertemporal utility function $U(\cdot)$, over which expectations are formed in the usual manner. ${ }^{22}$

In this specification, in a CTB with correlated risks, a subject chooses $c_{t}$ and $c_{t+k}$ to maximize:

$$
p U\left(\xi\left(c_{t}, c_{t+k}\right)\right)+(1-p) U(\xi(0,0))
$$

The tangency condition for an interior solution is now:

$$
\frac{p U^{\prime}\left(\xi\left(c_{t}, c_{t+k}\right)\right) D(t) u^{\prime}\left(c_{t}\right)}{p U^{\prime}\left(\xi\left(c_{t}, c_{t+k}\right)\right) D(t+k) u^{\prime}\left(c_{t+k}\right)}=(1+r)
$$

Once again, this does not depend upon the value of $p$, and in particular it remains unchanged when $p=1$ such that all payments are certain. This simple non-additive specification thus continues to predict identical choices under certainty as compared to correlated risks.

However, under independent risks $c_{t}$ and $c_{t+k}$ would be chosen to maximize:

$$
p\left[p U\left(\xi\left(c_{t}, c_{t+k}\right)\right)+(1-p) U\left(\xi\left(c_{t}, 0\right)\right)\right]+(1-p)\left[p U\left(\xi\left(0, c_{t+k}\right)\right)+(1-p) U(\xi(0,0))\right]
$$

In this case, the tangency condition becomes:

$$
\frac{p\left[p U^{\prime}\left(\xi\left(c_{t}, c_{t+k}\right)\right)+(1-p) U^{\prime}\left(\xi\left(c_{t}, 0\right)\right)\right] D(t) u^{\prime}\left(c_{t}\right)}{p\left[p U^{\prime}\left(\xi\left(c_{t}, c_{t+k}\right)\right)+(1-p) U^{\prime}\left(\xi\left(0, c_{t+k}\right)\right)\right] D(t+k) u^{\prime}\left(c_{t+k}\right)}=(1+r)
$$

Comparing this expression to (5), the expected marginal intertemporal utility of a payment received on date $t$ now incorporates an additional term corresponding to the case in which payment is received on date $t$ but not on date $t+k$, and vice-versa for the marginal utility of a payment received on date $t+k$. It is the consideration of these additional cases, not present in the correlated risks condition, that gives rise to the motive for intertemporal diversification under independent risks. As a result, the tangency condition in (6) is no longer invariant to the value of $p .^{23}$

\footnotetext{
${ }^{22}$ Andersen et al. adopt CRRA specifications for both the atemporal utility function $u(\cdot)$ and the intertemporal utility function $U(\cdot)$.

${ }^{23}$ The standard model is nested as the special case in which the intertemporal utility function $U(\cdot)$ is linear, such that $U^{\prime}(\cdot)$ is constant, in which case (6) collapses to (5) and so all three risk conditions are equivalent as before.
} 


\section{B Details of experimental parameters}

\section{B.1 Parameters of the multiple price list experiment}

Table B1 summarizes the parameters of the risk preference tasks in the MPL experiment. In each decision row, a subject was required to make a binary choice between Option A or Option B. Payoffs are expressed in AUD. At the time of the MPL experiment, one AUD was worth approximately USD 1.10. The expected value information in the final two columns was not presented to subjects.

Table B1: Risk Preference Decisions in the MPL Experiment.

\begin{tabular}{cccccccc}
\hline $\begin{array}{c}\text { Decision } \\
\text { Row }\end{array}$ & $\begin{array}{c}\text { Probability of } \\
\text { High Payoff }\end{array}$ & $\begin{array}{c}\text { Option A } \\
\text { High Payoff }\end{array}$ & $\begin{array}{c}\text { Option A } \\
\text { Low Payoff }\end{array}$ & $\begin{array}{c}\text { Option B } \\
\text { High Payoff }\end{array}$ & $\begin{array}{c}\text { Option B } \\
\text { Low Payoff }\end{array}$ & $\begin{array}{c}E V \text { of } \\
\text { Option A }\end{array}$ & $\begin{array}{c}E V \text { of } \\
\text { Option B }\end{array}$ \\
\hline 1 & 0.1 & 16 & 13 & 31 & 1 & 13.3 & 4.0 \\
2 & 0.2 & 16 & 13 & 31 & 1 & 13.6 & 7.0 \\
3 & 0.3 & 16 & 13 & 31 & 1 & 13.9 & 10.0 \\
4 & 0.4 & 16 & 13 & 31 & 1 & 14.2 & 13.0 \\
5 & 0.5 & 16 & 13 & 31 & 1 & 14.5 & 16.0 \\
6 & 0.6 & 16 & 13 & 31 & 1 & 14.8 & 19.0 \\
7 & 0.7 & 16 & 13 & 31 & 1 & 15.1 & 22.0 \\
8 & 0.8 & 16 & 13 & 31 & 1 & 15.4 & 25.0 \\
9 & 0.9 & 16 & 13 & 31 & 1 & 15.7 & 28.0 \\
10 & 1.0 & 16 & 13 & 31 & 1 & 16.0 & 31.0 \\
\hline 11 & 0.1 & 19 & 12 & 27 & 2 & 12.7 & 4.5 \\
12 & 0.2 & 19 & 12 & 27 & 2 & 13.4 & 7.0 \\
13 & 0.3 & 19 & 12 & 27 & 2 & 14.1 & 9.5 \\
14 & 0.4 & 19 & 12 & 27 & 2 & 14.8 & 12.0 \\
15 & 0.5 & 19 & 12 & 27 & 2 & 15.5 & 14.5 \\
16 & 0.6 & 19 & 12 & 27 & 2 & 16.2 & 17.0 \\
17 & 0.7 & 19 & 12 & 27 & 2 & 16.9 & 19.5 \\
18 & 0.8 & 19 & 12 & 27 & 2 & 17.6 & 22.0 \\
19 & 0.9 & 19 & 12 & 27 & 2 & 18.3 & 24.5 \\
20 & 1.0 & 19 & 12 & 27 & 2 & 19.0 & 27.0 \\
\hline
\end{tabular}


Table B1: Risk Preference Decisions in the MPL Experiment (continued).

\begin{tabular}{cccccccc}
\hline $\begin{array}{c}\text { Decision } \\
\text { Row }\end{array}$ & $\begin{array}{c}\text { Probability of } \\
\text { High Payoff }\end{array}$ & $\begin{array}{c}\text { Option A } \\
\text { High Payoff }\end{array}$ & $\begin{array}{c}\text { Option A } \\
\text { Low Payoff }\end{array}$ & $\begin{array}{c}\text { Option B } \\
\text { High Payoff }\end{array}$ & $\begin{array}{c}\text { Option B } \\
\text { Low Payoff }\end{array}$ & $\begin{array}{c}E V \text { of } \\
\text { Option A }\end{array}$ & $\begin{array}{c}E V \text { of } \\
\text { Option B }\end{array}$ \\
\hline 21 & 0.1 & 17 & 11 & 30 & 4 & 11.6 & 6.6 \\
22 & 0.2 & 17 & 11 & 30 & 4 & 12.2 & 9.2 \\
23 & 0.3 & 17 & 11 & 30 & 4 & 12.8 & 11.8 \\
24 & 0.4 & 17 & 11 & 30 & 4 & 13.4 & 14.4 \\
25 & 0.5 & 17 & 11 & 30 & 4 & 14.0 & 17.0 \\
26 & 0.6 & 17 & 11 & 30 & 4 & 14.6 & 19.6 \\
27 & 0.7 & 17 & 11 & 30 & 4 & 15.2 & 22.2 \\
28 & 0.8 & 17 & 11 & 30 & 4 & 15.8 & 24.8 \\
29 & 0.9 & 17 & 11 & 30 & 4 & 16.4 & 27.4 \\
30 & 1.0 & 17 & 11 & 30 & 4 & 17.0 & 30.0 \\
\hline 31 & 0.1 & 28 & 2 & 18 & 14 & 4.6 & 14.4 \\
32 & 0.2 & 28 & 2 & 18 & 14 & 7.2 & 14.8 \\
33 & 0.3 & 28 & 2 & 18 & 14 & 9.8 & 15.2 \\
34 & 0.4 & 28 & 2 & 18 & 14 & 12.4 & 15.6 \\
35 & 0.5 & 28 & 2 & 18 & 14 & 15.0 & 16.0 \\
36 & 0.6 & 28 & 2 & 18 & 14 & 17.6 & 16.4 \\
37 & 0.7 & 28 & 2 & 18 & 14 & 20.2 & 16.8 \\
38 & 0.8 & 28 & 2 & 18 & 14 & 22.8 & 17.2 \\
39 & 0.9 & 28 & 2 & 18 & 14 & 25.4 & 17.6 \\
40 & 1.0 & 28 & 2 & 18 & 14 & 28.0 & 18.0 \\
\hline
\end{tabular}


Table B2 summarizes the parameters of the time preference tasks in the MPL experiment. In each decision row, a subject was required to make a binary choice between Option A or Option B. Delay lengths are expressed here in days, although they were presented to subjects in terms of weeks, and payments are expressed in AUD. The gross interest rate information in the final column was not presented to subjects.

Each decision was faced under two different risk conditions: one in which all payments were certain, and one in which payments were received with $50 \%$ probability. Half of the subjects completed the discounting tasks under certainty before the discounting tasks under risk, while for the other half this order was reversed.

Table B2: Time Preference Decisions in the MPL Experiment.

\begin{tabular}{cccccc}
\hline $\begin{array}{c}\text { Decision } \\
\text { Row }\end{array}$ & $\begin{array}{c}\text { Front-end Delay }(t) \\
\text { to Sooner Option }\end{array}$ & $\begin{array}{c}\text { Further Delay }(k) \\
\text { to Later Option }\end{array}$ & $\begin{array}{c}\text { Sooner Payment } \\
(\text { Option A })\end{array}$ & $\begin{array}{c}\text { Later Payment } \\
(\text { Option B })\end{array}$ & $\begin{array}{c}\text { Gross Interest } \\
\text { Rate }(1+r)\end{array}$ \\
\hline 1 & 7 & 21 & 20 & 21 & 1.05 \\
2 & 7 & 21 & 20 & 22 & 1.10 \\
3 & 7 & 21 & 20 & 23 & 1.15 \\
4 & 7 & 21 & 20 & 24 & 1.20 \\
5 & 7 & 21 & 20 & 25 & 1.25 \\
6 & 7 & 21 & 20 & 26 & 1.30 \\
7 & 7 & 21 & 20 & 27 & 1.35 \\
8 & 7 & 21 & 20 & 28 & 1.40 \\
9 & 7 & 21 & 20 & 29 & 1.45 \\
10 & 7 & 21 & 20 & 30 & 1.50 \\
\hline 11 & 7 & 42 & 20 & 30 & 1.50 \\
12 & 7 & 42 & 21 & 30 & 1.43 \\
13 & 7 & 42 & 22 & 30 & 1.36 \\
14 & 7 & 42 & 23 & 30 & 1.30 \\
15 & 7 & 42 & 24 & 30 & 1.25 \\
16 & 7 & 42 & 25 & 30 & 1.20 \\
17 & 7 & 42 & 26 & 30 & 1.15 \\
18 & 7 & 42 & 27 & 30 & 1.11 \\
19 & 7 & 42 & 29 & 30 & 1.07 \\
20 & 7 & & & 30 & 1.03 \\
\hline & 7 & & 29 & & \\
\hline
\end{tabular}


Table B2: Time Preference Decisions in the MPL Experiment (continued).

\begin{tabular}{cccccc}
\hline $\begin{array}{c}\text { Decision } \\
\text { Row }\end{array}$ & $\begin{array}{c}\text { Front-end Delay }(t) \\
\text { to Sooner Option }\end{array}$ & $\begin{array}{c}\text { Further Delay }(k) \\
\text { to Later Option }\end{array}$ & $\begin{array}{c}\text { Sooner Payment } \\
(\text { Option A })\end{array}$ & $\begin{array}{c}\text { Later Payment } \\
(\text { Option B })\end{array}$ & $\begin{array}{c}\text { Gross Interest } \\
\text { Rate }(1+r)\end{array}$ \\
\hline 21 & 7 & 63 & 20 & 21 & 1.05 \\
22 & 7 & 63 & 20 & 22 & 1.10 \\
23 & 7 & 63 & 20 & 23 & 1.15 \\
24 & 7 & 63 & 20 & 24 & 1.20 \\
25 & 7 & 63 & 20 & 25 & 1.25 \\
26 & 7 & 63 & 20 & 26 & 1.30 \\
27 & 7 & 63 & 20 & 27 & 1.35 \\
28 & 7 & 63 & 20 & 28 & 1.40 \\
29 & 7 & 63 & 20 & 29 & 1.45 \\
30 & 7 & 63 & 20 & 30 & 1.50 \\
\hline 31 & 7 & 84 & 20 & 30 & 1.50 \\
32 & 7 & 84 & 21 & 30 & 1.43 \\
33 & 7 & 84 & 22 & 30 & 1.36 \\
34 & 7 & 84 & 23 & 30 & 1.30 \\
35 & 7 & 84 & 24 & 30 & 1.25 \\
36 & 7 & 84 & 25 & 30 & 1.20 \\
37 & 7 & 84 & 26 & 30 & 1.15 \\
38 & 7 & 84 & 27 & 30 & 1.11 \\
39 & 7 & & 29 & 30 & 1.07 \\
40 & 7 & & & 30 & 1.03 \\
\hline & 7 & 84 & & & \\
\hline
\end{tabular}




\section{B.2 Parameters of the convex time budget experiment}

Table B3 summarizes the parameters of the CTB experiment. In each decision row, a subject was required to allocate an endowment of 100 tokens between Payment A (received on date $t$ ) and Payment $\mathrm{B}$ (received on date $t+k$ ). Delay lengths are expressed here in days, although they were presented to subjects in terms of weeks, and token exchange rates are expressed in AUD. Consistent with A\&S, the gross interest rate information in the final column was not presented to subjects. These parameters are identical to those in A\&S Table 1, except that the delay lengths were changed from 28 and 56 days in A\&S to 35 and 70 days to avoid a public holiday, and that payments were denominated in AUD instead of USD. At the time of the CTB experiment, one AUD was worth approximately USD 1.05 .

Each decision was faced under three different risk conditions: one in which all payments were certain, one in which the sooner and later payments were received with $50 \%$ probability as realized by two independent lotteries, and one in which the sooner and later payments were received with $50 \%$ probability as realized by a single lottery. Half of the subjects completed these three risk conditions in the order Independent-Certain-Correlated, while for the other half this order was reversed.

Table B3: Decision Parameters for the CTB Experiment.

\begin{tabular}{ccccccc}
\hline $\begin{array}{c}\text { Decision } \\
\text { Row }\end{array}$ & $\begin{array}{c}\text { Front-end } \\
\text { Delay }(t)\end{array}$ & $\begin{array}{c}\text { Further } \\
\text { Delay }(k)\end{array}$ & $\begin{array}{c}\text { Token } \\
\text { Endowment }\end{array}$ & $\begin{array}{c}\text { Sooner } \\
\text { Token Value }\end{array}$ & $\begin{array}{c}\text { Later } \\
\text { Token Value }\end{array}$ & $\begin{array}{c}\text { Gross Interest } \\
\text { Rate }(1+r)\end{array}$ \\
\hline 1 & 7 & 35 & 100 & 0.20 & 0.20 & 1.00 \\
2 & 7 & 35 & 100 & 0.19 & 0.20 & 1.05 \\
3 & 7 & 35 & 100 & 0.18 & 0.20 & 1.11 \\
4 & 7 & 35 & 100 & 0.17 & 0.20 & 1.18 \\
5 & 7 & 35 & 100 & 0.16 & 0.20 & 1.25 \\
6 & 7 & 35 & 100 & 0.15 & 0.20 & 1.33 \\
7 & 7 & 35 & 100 & 0.14 & 0.20 & 1.43 \\
\hline 8 & 7 & 70 & 100 & 0.20 & 0.20 & 1.00 \\
9 & 7 & 70 & 100 & 0.19 & 0.20 & 1.05 \\
10 & 7 & 70 & 100 & 0.18 & 0.20 & 1.11 \\
11 & 7 & 70 & 100 & 0.17 & 0.20 & 1.18 \\
12 & 7 & 70 & 100 & 0.16 & 0.20 & 1.25 \\
13 & 7 & 70 & 100 & 0.15 & 0.20 & 1.33 \\
14 & 7 & 70 & 100 & 0.14 & 0.20 & 1.43 \\
\hline
\end{tabular}




\section{Instructions for the multiple price list experiment ELIGIBILITY TO PARTICIPATE}

Welcome to today's session, and thank you for coming here on time. Please do not talk to the other participants while the session is in progress. Mobile phones must also be turned off. If you have a question, please raise your hand, and one of us will come to you to answer it in private.

In this study, there is a chance you may receive part of your payment in the future.

Therefore, to be eligible to participate, you must be willing to receive this part of your payment by cheque, to be written to you by Dr Stephen Cheung, a Lecturer in the School of Economics. This cheque would be drawn on the University of Sydney branch of the National Australia Bank.

The cheque would be delivered by Express Post to your nominated residential mailing address in Sydney, at a date that depends on both your decisions in the study, and on chance. The latest you could receive this payment is thirteen weeks from today, in the last week of classes in Semester two.

Therefore, to take part in this study, you must be willing to provide your name and residential mailing address in Sydney. This information will only be seen by Dr Cheung and his assistants.

After payment has been sent, this information will no longer be retained. Your identity will not be a part of any subsequent data analysis.

Finally, you must be willing to stay for the full duration of today's session; otherwise you will not receive any payment at all.

If you do not agree to all of these points, please raise your hand now.

If you agree, please turn over this page to sign the consent form, and hand it in now.

\section{GENERAL INFORMATION AND EARNINGS}

This study is financed by the Faculty of Arts and Social Sciences and concerns the economics of decision making. The instructions are simple, and you will benefit from considering them carefully.

In this study you will make a total of 120 choices involving amounts of money that differ with respect to the time when money is received, and/or the chances of receiving the money. These decisions will be divided into two sets. There are 40 choices in Decision Set I, and 80 choices in Decision Set II.

These decisions are not designed to test you - the only correct answers are the ones that you really think are best for you.

Afterwards, we will ask you to complete a questionnaire about yourself. This information is for our records only. Our records and the results of our research will not identify any individual or the choices he or she made in any way. All records will be linked to an anonymous ID number only.

At the end, we will call you into the office, one at a time, to calculate your earnings. 
You will be paid $\$ 5$ for participating, and you can also earn a considerable amount in addition to this. How much you earn will depend partly on chance and partly on the choices that you make. Your earnings from the study are made up of three parts.

- Firstly, we will pay a participation fee of $\$ 5$ if you submit valid responses for all 120 decisions as well as the questionnaire. This will be paid to you in cash at the end of the session.

- Secondly, you will be paid according to your choice in one randomly-selected decision from Decision Set I. The amount you receive will depend on both the choice that you made, as well as on chance. This amount will also be paid to you in cash at the end of the session.

- Thirdly, you will be paid according to your choice in one randomly-selected decision from Decision Set II. The date of this payment depends on the choice that you made, while the amount depends on both your choice as well as on chance.

In some choices in Decision Set II there is a possibility - to be decided by chance - that you may not receive any payment at all. If the decision that is chosen to count involves chance, we will roll a ten-sided die at the end of the session to determine whether or not any payment is made.

This means that you will be told whether or not you will receive any payment in Decision Set II - and if so, how much and when - before you leave today.

If it is determined that you will receive a payment in Decision Set II, it will be sent to you by cheque, delivered by Express Post to your nominated residential mailing address in Sydney, on a date determined by your own choice.

\section{DECISION SET I}

In Decision Set I, you will make choices between two options labelled "A" and "B". We will present you with 40 of these decisions.

All decisions have the same format. The only difference is that the amounts of money in Options $\mathrm{A}$ and $\mathrm{B}$, and the chances that each amount will be paid, will differ from one decision to the next.

The 40 choices are further divided into four sets of ten. Within each set of ten decisions the amounts of money remain the same, and it is only the chances that each amount will be paid that change.

You will be paid according to your choice in one of the 40 decisions in Decision Set I. At the time you make your choices you will not know which decision will be selected for payment. Since all decisions are equally likely to be chosen, you should treat each decision as if it may be the decision that counts.

At the end of the session, we will roll a four-sided die and a ten-sided die to randomly determine which one of the 40 decisions will be the one that counts. The payment that you receive will be determined by the choice that you made - either Option A or Option B - in the selected decision.

We will then roll the ten-sided die a second time to determine what payment you will receive, based upon your choice of Option A or B. This amount will be added to your $\$ 5$ participation fee, and paid to you in cash at the end of the session. 
Now please look at the first Decision Table on the next page.

This Decision Table shows ten decisions. Each decision is a paired choice between "Option A" and "Option B". You will be asked to make a choice between these two options in each decision row.

Before you start making your choices, let us explain how these choices affect your earnings. We will use a ten-sided die to determine payoffs; the faces are numbered from 1 to 10 (the "0" face of the die will serve as 10). Now, please look at Decision 1 at the top of the table.

Option A pays $\$ 16$ if the roll of the ten-sided die is 1 , and $\$ 13$ if the roll is $2-10$. Option B pays $\$ 31$ if the roll of the die is 1 , and $\$ 1$ if the roll is $2-10$.

The other decisions are similar, except that as you move down the table, the chances of the higher payoff in each option increase. In fact, for Decision 10 in the bottom row, the die will not be needed since each option pays the higher payoff for sure, so your choice here is between $\$ 16$ and $\$ 31$.

For each of these ten decisions, you are asked to choose Option A or Option B by marking an "X" in the appropriate box in each row. You may choose A for some decision rows and B for other rows, and you may make your decisions in any order.

The other Decision Tables are similar, except that the amounts of money offered in Options A and $\mathrm{B}$ will differ in each table.

One of the 40 decisions in Decision Set I will be randomly selected in the end to count toward

your earnings. You will not know in advance which decision will be used. Each decision has an equal chance of being used in the end.

Your earnings from Decision Set I will be determined at the end of the session, when you are called into the office to be paid.

- Firstly, we will roll a four-sided die to decide which of the four Decision Tables will count.

- Next, we will roll a ten-sided die to decide which of the ten rows in the chosen table will count. (If this roll of the die is " 0 " then the tenth row will be chosen.)

- Finally, we will roll the ten-sided die a second time to determine your earnings for the option that you chose, either Option A or Option B, in the decision selected by the first two die rolls. For example, if the roll of the four-sided die is 2, then Decision Table 2 is chosen. If the first roll of the ten-sided die is 8, then Decision 18 is chosen to count. Finally, if the second roll of the ten-sided die is 4 , then your earnings would be $\$ 19$ if you chose Option A, or $\$ 27$ if you chose Option B.

Please make your choices by marking an " $\mathrm{X}$ " in the appropriate box in each row of each Decision Table. If you have a question, please raise your hand, and one of us will come to assist you in private.

\section{DECISION SET II}

In Decision Set II, you will make choices between two options labelled "A" and "B". These choices involve receiving money at two different points in time. In each case Option A is "sooner" and 
Option B is "later". We will present you with 80 of these decisions.

All decisions have the same format. They differ in the amounts of money and payment dates, as well as the chances that the payments will be made. You could receive payment as early as one week from today, or as late as the last week of classes in Semester two, or another date in between.

It is important to note that some of these payments involve chance. In some decisions, there is a possibility that you may not receive any payment at all. You will be fully informed of the chances associated with the two options at the time that you make each decision.

The 80 choices are further divided into eight sets of ten. Within each set of ten decisions, the payment dates and chances that payments are made remain the same. It is only the amounts of money in Options A and B that change.

You will be paid according to your choice in one of the 80 decisions in Decision Set II. At the time you make your choices you will not know which decision will be selected for payment. Since all decisions are equally likely to be chosen, you should treat each decision as if it may be the decision that counts.

At the end of the session we will roll an eight-sided die and a ten-sided die to randomly determine which one of the 80 decisions will be the one that counts. The amount and date of your payment will be determined by the choice that you made - either Option A or Option B - in the selected decision.

If the decision that is chosen to count involves chance, we will roll the ten-sided die again to determine whether any payment is made. This means that you will be told whether or not you will receive any payment in Decision Set II - and if so, how much and when - before you leave today.

If it is determined that you will receive a payment, it will be sent to you by cheque, by Express Post to your nominated residential mailing address in Sydney, on the date specified by your choice.

One business day before the scheduled payment date, the cheque will dispatched for delivery by Express Post by Dr Cheung and his assistants. Australia Post guarantees next business day delivery for mail sent by Express Post to addresses within the Sydney metropolitan region.

Attached to your Participation Information Statement is Dr Cheung's business card. Please keep this in a safe place. If it is determined that you will receive a payment by cheque, but you do not receive your cheque on the nominated date, you should contact Dr Cheung.

To process payment by cheque, we will need to collect your name and residential mailing address in Sydney. This will only be seen by Dr Cheung and his assistants. After payment has been sent, this information will no longer be retained. Your identity will not be a part of subsequent data analysis.

Now please turn to the first Decision Table on the next page.

This Decision Table shows ten decisions. Each decision is a paired choice between "Option A" and "Option B". You will be asked to make a choice between these two options in each decision row.

Option A pays $\$ 20$ one week from today if the roll of a ten-sided die is $1-5$, or nothing otherwise. Option B pays $\$ 21$ four weeks from today if the roll of the die is $1-5$, or nothing otherwise. 
The other decisions are similar, except that as you move down the table, the amount of money offered in Option B increases.

For each of these ten decisions, you are asked to choose Option A or Option B by marking an "X" in the appropriate box in each row. You may choose A for some decision rows and B for other rows, and you may make your decisions in any order.

The other seven Decision Tables are similar except that the payment dates, amounts of money, and chances that payments will be made, will differ in each table.

Although you will make 80 decisions in Decision Set I, only one of these will be randomly selected in the end to count toward your earnings. You will not know in advance which decision will be used. Each decision has an equal chance of being used in the end.

Your earnings from Decision Set II will be determined at the end of the session, when you are called into the office to be paid.

- Firstly, we will roll an eight-sided die to decide which of the eight Decision Tables will count.

- Next, we will roll a ten-sided die to decide which of the ten rows in the chosen table will count. (If this roll of the die is "0" then the tenth row will be chosen.)

- Finally, if the decision that is chosen to count involves chance, we will roll the ten-sided die a second time to determine whether or not any payment is made. If a payment is to be made, the amount and date are determined by the choice that you made in the selected decision.

For example, if the roll of the eight-sided die is 2, then Decision Table 2 is chosen. If the first roll of the ten-sided die is 8 , then Decision 18 is chosen to count.

Finally, if the second roll of the ten-sided die is 4 , then you would receive $\$ 27$ one week from today you chose Option A, or $\$ 30$ seven weeks from today if you chose Option B. However, if the second roll of the ten-sided die were 6 , then you would not receive any payment.

Please make your choices by marking an " $\mathrm{X}$ " in the appropriate box in each row of each Decision Table. If you have a question, please raise your hand, and one of us will come to assist you in private. 


\section{Instructions for the convex time budget experiment ELIGIBILITY TO PARTICIPATE}

Welcome to today's session, and thank you for coming here on time. Please do not talk to the other participants while the session is in progress. Mobile phones must also be turned off. If you have a question, please raise your hand, and someone will come to you to answer it in private.

\section{In this study, you will receive all of your payments in the future.}

Therefore, to be eligible to participate, you must be willing to receive your payments by cheque, to be written to you by Dr Stephen Cheung, a Lecturer in the School of Economics. These cheques will be drawn on the University of Sydney branch of the National Australia Bank.

The cheques will be delivered by Express Post to your nominated residential mailing address in Sydney, on two dates that depend on both your decisions in the study, and on chance. The first payment will come one week from today. The latest that you could receive the second payment is eleven weeks from today, in the last week of classes this semester.

Therefore, to take part in this study, you must be willing to provide your name and residential mailing address in Sydney. This information will only be seen by Dr Cheung and his assistants.

After payment has been sent, this information will no longer be retained. Your identity will not be a part of any subsequent data analysis.

Finally, you must be willing to stay for the full duration of today's session; otherwise you will not receive any payment at all.

If you do not agree to all of these points, please raise your hand now.

\section{If you agree, please turn over this page to sign the consent form, and hand it in now.}

\section{EARNINGS}

For completing today's study, you will receive a minimum of $\$ 10$. You will receive this in two payments of $\$ 5$, which will arrive on two different dates. The first payment will come one week from today. The second will be on a date to be determined by chance, as explained below.

You may also receive additional earnings from the study. These depend on both your own decisions, as well as on chance. They would be added to one or both of your two minimum payments of $\$ 5$.

Today you will make 42 choices, but only one of them will be randomly selected at the end to count toward your earnings.

In each choice, you must decide how to allocate money between two points in time; one date is "sooner" and the other is "later". This means you could receive payments as early as one week from today, as late as the last week of classes this semester, or another date in between.

It is important to note that some of these decisions involve chance. There is a chance that your sooner payment, your later payment or both payments may not be sent at all. 
- In one-third of the decisions, whether or not you receive the sooner payment is determined by rolling a purple ten-sided die, while the later payment is determined by a white ten-sided die. Therefore in these decisions, the two payments are determined by two separate die rolls.

- In one-third of the decisions, both payments are determined by a single die roll. In these decisions, both the sooner and later payments are determined by rolling the white ten-sided die.

- Finally, in one-third of the decisions, the payments do not depend on any die roll at all.

The nature of these chances will always be clearly indicated at the top of each decision sheet.

Once all 42 decisions have been made, we will draw a numbered ball from the bingo cage. This will determine which decision will be the one that counts, and the corresponding payment dates.

We will use this decision to determine your earnings. Since every decision is equally likely to be chosen, you should treat each decision as if it may be the one that counts.

If the decision that is chosen to count involves chance, we will then determine whether or not you receive the payments by rolling the ten-sided die. This means that you will be told whether or not you will receive these payments before you leave today.

Your earnings from the decision that counts will be added to the two minimum payments of $\$ 5$ each. If, by chance, one or both of your payments is not sent, you will receive only the $\$ 5$ payment on that date. Thus, you will always receive at least $\$ 5$ on the sooner date and at least $\$ 5$ on the later date.

One business day before each scheduled payment date, a cheque will dispatched for delivery by Express Post by Dr Cheung and his assistants. Australia Post guarantees next business day delivery for mail sent by Express Post to addresses within the Sydney metropolitan region.

Attached to your Participation Information Statement is Dr Cheung's business card. Please keep this in a safe place. If you do not receive one of your cheques on the designated date, please contact Dr Cheung.

\section{INSTRUCTIONS}

In each decision you are asked to divide 100 tokens between two payments at two different dates: Payment A (which is sooner) and Payment B (which is later).

Tokens will be exchanged for money. The tokens you allocate to Payment B (later) will always be worth at least as much as the tokens you allocate to Payment A (sooner).

The sample decision below is similar to the ones you will make today. It shows the choice to allocate 100 tokens between Payment A on 27 March and Payment B on 10 April. In the example, each token allocated to 27 March is worth $\$ 0.10$, while each token allocated to 10 April is worth $\$ 0.15$. You may allocate some tokens to the sooner date and some to the later date.

Example: If you were to allocate 62 tokens to 27 March and 38 tokens to 10 April, then you would have the chance to receive $62 \times \$ 0.10=\$ 6.20$ on 27 March $(+\$ 5$ minimum payment $)$ and the chance to receive $38 \times \$ 0.15=\$ 5.70$ on 10 April $(+\$ 5$ minimum payment). 
Today's date will always be highlighted in red on the calendar. The sooner date will be marked in green, and the later date in blue. The dates will also be indicated in the table on the right.

In the actual study, there are seven decisions on each table, and you will complete six tables in total.

\section{Chance of receiving payments:}

Each decision sheet also shows the chances that each payment is sent. In the example, Payment A would be sent if the roll of the purple ten-sided die is between 1 and 7 , while Payment $\mathrm{B}$ would be sent if the roll of the white ten-sided die is between 1 and 3.

In each decision we will inform you of the exact nature of the die rolls that determine whether your payments are sent. If this decision was chosen as the one that counts, we would determine the actual payments by rolling the ten-sided die.

Example: Suppose that you allocated 62 tokens to 27 March and 38 tokens to 10 April. If this decision was chosen as the one that counts, we would roll both the purple and white ten-sided die.

- If the purple die landed on $1,2,3,4,5,6$, or 7, Payment A would be sent and you would receive $\$ 6.20$ ( $+\$ 5$ minimum payment) on 27 March. If the purple die on landed on 8,9 , or 0 , Payment A would not be sent and you would receive only the $\$ 5$ minimum payment on 27 March.

- If the white die landed on 1,2 , or 3 , Payment B would be sent and you would receive $\$ 5.70(+$ $\$ 5$ minimum payment) on 10 April. If the white die landed on $4,5,6,7,8,9$, or 0 , Payment $\mathrm{B}$ would not be sent and you would receive only the $\$ 5$ minimum payment on 10 April.

\section{SUMMARY}

- You will receive a minimum of $\$ 10$, in two payments of $\$ 5$ which will arrive on two different dates. Any additional payments will be added to one or both of the two minimum payments.

- You will make a total of 42 decisions, and one of them will be randomly selected at the end to determine your earnings.

- You will always allocate exactly 100 tokens. Tokens that you allocate to Payment A (sooner) and Payment B (later) will be exchanged for money at different rates. The tokens you allocate to Payment B will always be worth at least as much as the ones you allocate to Payment A.

- Payment A and Payment B will have varying degrees of chance. In some choices they depend on two separate die rolls, in some they depend on a single die roll, and in some they do not depend on any die roll. You will be fully informed of the exact nature of these chances.

- On each decision sheet you will make seven decisions. For each decision you will allocate 100 tokens. Allocate exactly 100 tokens in each decision: no more, no less. 
- At the end of the session, a random number will be drawn from the bingo cage to determine which decision will be the one that counts. Because each decision is equally likely to be chosen, you should treat each decision as if it may be the one that determines your payments.

- If necessary, we will then roll one or two ten-sided die to determine whether or not the payments you chose will actually be sent.

- Your payments, by cheque, will be sent to the address you provide.

- Each cheque will be dispatched by Express Post one business day before payment is due. Australia Post guarantees next business day delivery.

- You have been given the business card of Dr Stephen Cheung. Keep this card in a safe place and contact Dr Cheung immediately if one of your payments is not received.

Reminder: Please make sure that the total tokens you allocate between Payment A and Payment B sum to exactly 100 tokens in each row.

On your desk are two envelopes: one for the sooner payment and one for the later payment. Please take the time now to address these to yourself at your own residential mailing address in Sydney. 
E Sample decision sheet from the CTB experiment

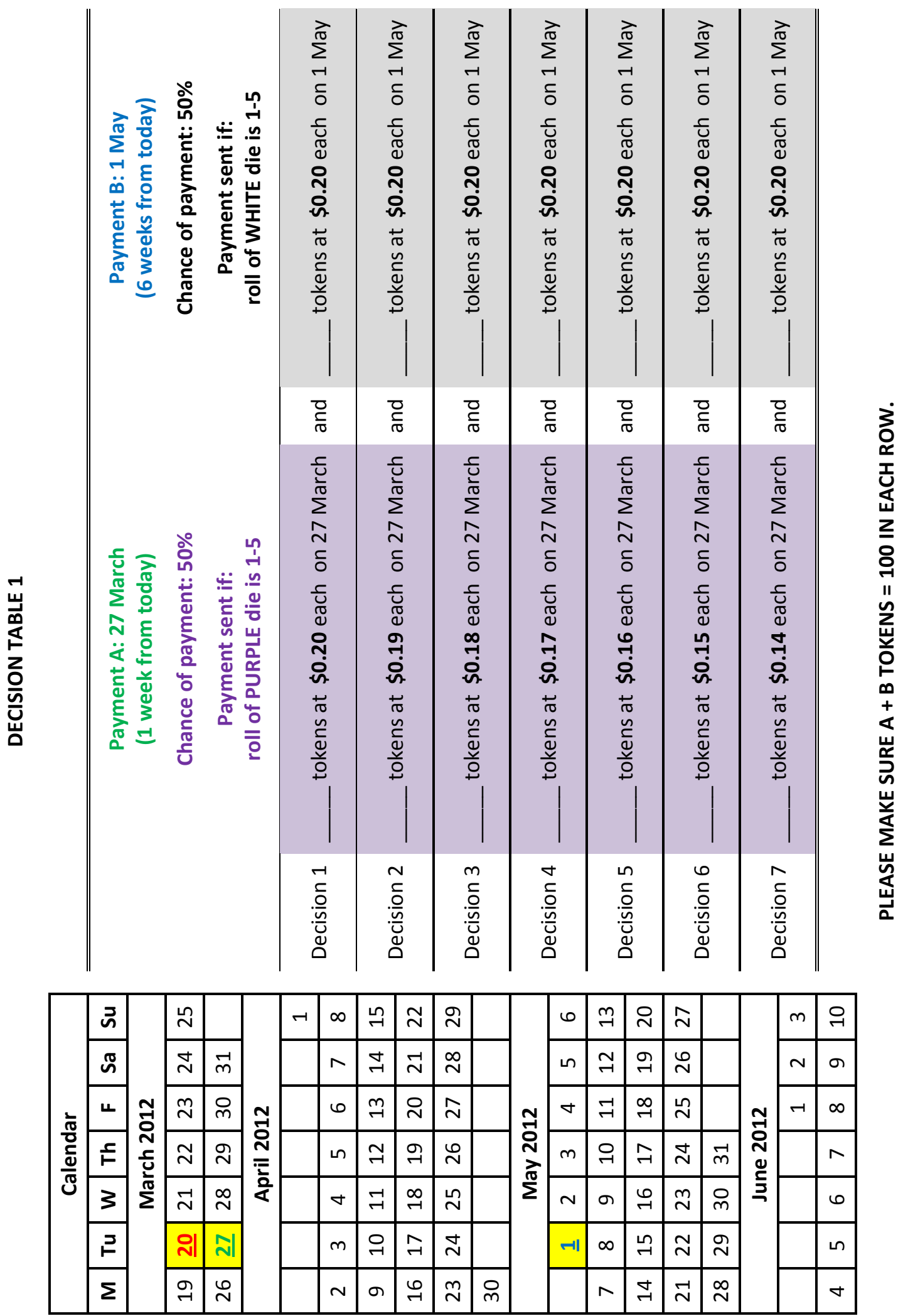

